\title{
Marco legal do Programa Nacional de Alimentação Escolar: uma releitura para alinhar propósitos e práticas na aquisição de alimentos ${ }^{1}$
}

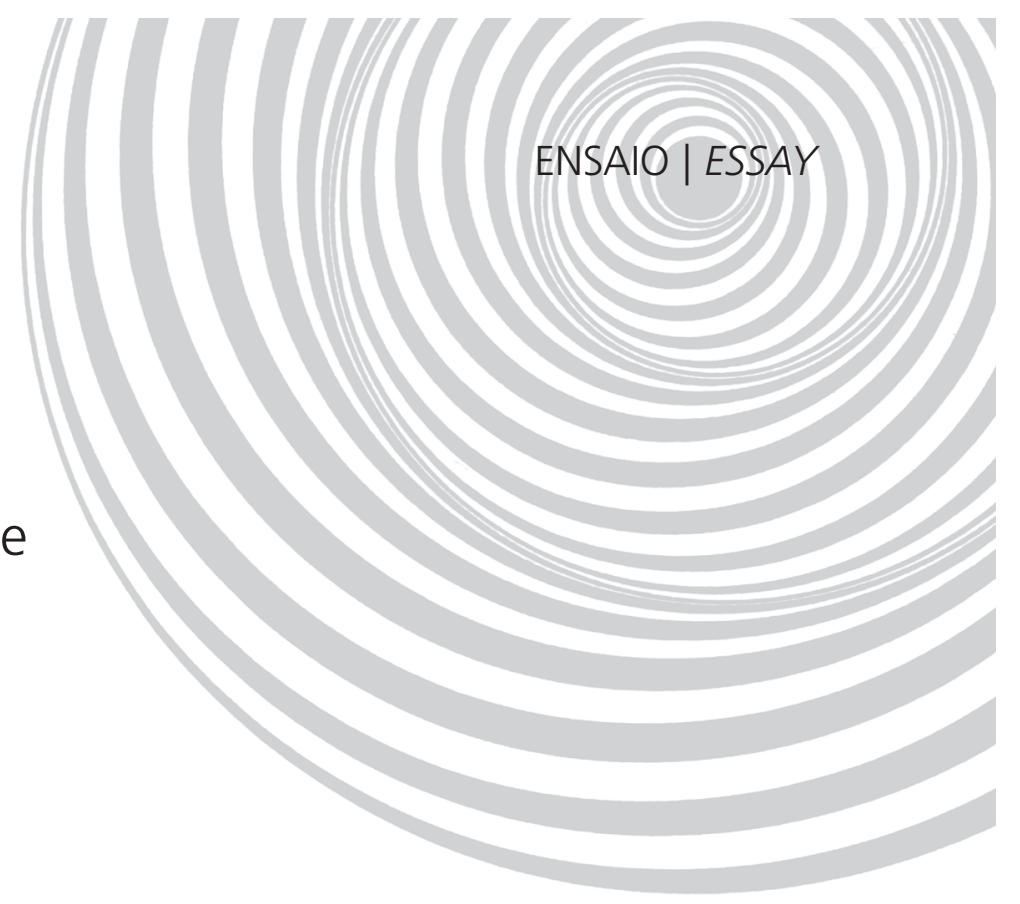

\author{
a new reading for aligning purposes and \\ practices in food acquisition
}

Legal framework of the National School Feeding Program:

Carla Rosane Paz Arruda TEO²

Carlos Augusto MONTEIRO3

RE S U M O

Este ensaio pretende discutir a aquisição de alimentos para o Programa Nacional de Alimentação Escolar à luz do seu marco legal vigente, na perspectiva de promover hábitos alimentares saudáveis e culturalmente articulados que contribuam para a promoção das condições de saúde da população escolar brasileira e para o desenvolvimento local. Apresenta-se análise da legislação em vigor do Programa Nacional de Alimentação Escolar, evidenciando a intencionalidade de influenciar o sistema alimentar brasileiro e o padrão alimentar de sua população a partir da alimentação escolar, destacando-se as lacunas que desafiam a efetivação de mudanças substanciais na execução do programa. Partindo dessa análise e com base no elevado e crescente consumo de alimentos ultraprocessados no Brasil, e considerando as desvantagens desses alimentos diante de alimentos pouco ou não processados, desenvolve-se proposta para orientar a construção de uma pauta de alimentos que seja consistente com o marco legal vigente do programa e com seus objetivos. Argumenta-se que a predominância de alimentos pouco ou não processados na alimentação escolar pode ser estratégia para o resgate do patrimônio alimentar saudável e para o fortalecimento do desenvolvimento local se resultar da aproximação com a agricultura familiar.

Termos de indexação: Nutrição em saúde pública. Políticas públicas. Programas e políticas de nutrição e alimentação.

1 Apoio: Conselho Nacional de Desenvolvimento Científico e Tecnológico (Processo no 102231/2011-7).

2 Universidade Comunitária da Região de Chapecó, Área de Ciências da Saúde, Programa de Pós-Graduação em Ciências da Saúde. Av. Senador Attílio Fontana, 591-E, Efapi, 89809-000, Chapecó, SC, Brasil. Correspondência para/Correspondence to: CRPA TEO.E-mail: <carlateo@unochapeco.edu.br>.

${ }^{3}$ Universidade de São Paulo, Faculdade de Saúde Pública, Núcleo de Pesquisas Epidemiológicas em Nutrição e Saúde. São Paulo, SP, Brasil. 


\section{A B S T R A C T}

This essay aims to discuss the acquisition of food by the National School Feeding Program in light of its current legal framework with a view to promote healthy and culturally sound eating habits that help to improve the health of Brazilian school children and promote local development. The study presents an analysis of the current legislation of the National School Feeding Program, evidencing its intention to influence the Brazilian feeding system and the food pattern of its population using school meals, highlighting the gaps that challenge the achievement of major changes in the execution of the program. From this analysis and based on the high and growing consumption of ultra-processed foods in Brazil, and considering the disadvantages of these foods when compared with minimally-processed or fresh foods, a proposal is developed to guide the construction of a list of foods that is consistent with the current legal framework of the Program and its objectives. It is argued that the prevalence of minimally-processed or fresh foods in school meals can be a strategy to rescue the healthy-food heritage and strengthen local development if promoting family farming.

Indexing terms: Nutrition, public health. Public policies. Nutrition programs and policies.

\section{N T R O D U Ç Ã O}

O Programa Nacional de Alimentação Escolar (PNAE) é o mais antigo programa de alimentação e nutrição em vigência ininterrupta no Brasil, tendo origem na década de 1940 e marco legal fundado na de 1950'. Ao longo desse percurso histórico, o PNAE tem apresentado avanços significativos com relação a seus objetivos, gestão, execução, abrangência e articulação com outros setores além da educação².

Recentemente, a base legal do programa foi revisada, com a aprovação da Lei $n^{\circ}$ $11.947 / 2009^{3}$. Entre os avanços decorrentes, destacam-se o apoio explícito ao desenvolvimento sustentável, pela articulação com a agricultura familiar, e a proibição e a restrição da aquisição de alimentos menos saudáveis. Porém, a recomendação, dada pela regulamentação anterior ${ }^{4,5}$, para que fosse conferida preferência a alimentos básicos in natura ou semielaborados foi suprimida, o que pode resultar em prejuízo para os objetivos do programa.

Nas últimas décadas, a substituição de alimentos básicos in natura ou pouco processados por alimentos de maior extensão de processamento é uma tendência que vem se consolidando em estreita relação com os modos de vida contemporâneos, decorrentes da industrialização e da urbanização intensas. Nesse processo de transformação da vida em sociedade, o consumo de alimentos tradicionais vem perdendo espaço para o de alimentos poupadores de tempo ${ }^{6}$. Esses alimentos, notadamente processados, de alta densidade energética, ricos em açúcar, sódio e gorduras, vêm se incorporando às práticas alimentares com forte suporte publicitário, delineando um padrão alimentar que está na base do aumento da prevalência de excesso de peso, de obesidade e de doenças associadas ${ }^{7-9}$.

Ao considerar essa complexificação do perfil alimentar e nutricional da população brasileira, a alimentação escolar assume papel importante pelo potencial que apresenta na reconfiguração desse quadro, especialmente por ser na infância e na adolescência que se estabelecem mais fortemente hábitos alimentares com maiores possibilidades de perdurarem na vida adulta ${ }^{10}$.

Nesse contexto, e assumindo o pressuposto de que a base legal vigente do PNAE representa uma oportunidade ímpar para a construção de uma cadeia alimentar diferenciada, o objetivo deste trabalho é discutir as implicações dessas orientações legais para a aquisição de alimentos no âmbito do programa, provocando o debate sobre os avanços conquistados e sobre as lacunas identificadas como desafios na atual legislação. Sugere-se uma releitura da base legal do PNAE que concorra para a promoção de hábitos alimentares mais saudáveis, fundamentados no respeito à cultura alimentar, e que contribua para a superação do panorama epidemiológico atual. 


\section{O marco legal atual do PNAE}

O marco legal do PNAE está assentado, atualmente, na Lei $n^{\circ} 11.947 / 2009^{3}$ e na Resolução/CD/FNDE n 38/200911. Dentro do escopo deste trabalho, interessa destacar três das diretrizes que essa base legal apresenta. Primeiramente, a que estabelece o emprego de "alimentação saudável e adequada, compreendendo o uso de alimentos variados, seguros, que respeitem a cultura, as tradições e os hábitos alimentares saudáveis" (Art. $2^{\circ}$, inciso I) ${ }^{3}$. A segunda diretriz destacada inova ao ampliar a abrangência da educação alimentar e nutricional, apresentando uma concepção que articula teoria e prática quando indica sua inclusão "no processo de ensino e aprendizagem, que perpassa pelo currículo escolar, abordando o tema alimentação e nutrição e o desenvolvimento de práticas saudáveis de vida" (Art. $2^{\circ}$, inciso II) ${ }^{3}$. Finalmente, destaca-se a diretriz que explicita o apoio ao desenvolvimento sustentável, e que exige que sejam aplicados "incentivos para a aquisição de gêneros alimentícios diversificados, produzidos em âmbito local e preferencialmente pela agricultura familiar" (Art. $2^{\circ}$, inciso $\mathrm{V})^{3}$.

Como desdobramento dessas diretrizes, a legislação determina que os cardápios do programa sejam elaborados de acordo com o perfil epidemiológico da população atendida e utilizem alimentos básicos integrantes da tradição alimentar local, a partir de escolhas pautadas na sustentabilidade e na vocação e diversificação agrícola da região. Segundo essa legislação, alimentos básicos são aqueles indispensáveis à promoção de uma alimentação saudável ${ }^{3,11}$ : essa definição, bastante ampla, confere flexibilidade à composição da pauta de alimentos e elaboração de cardápios para o programa.

Outro desdobramento relevante para a discussão proposta é a exigência de que pelo menos 30\% dos recursos recebidos do Fundo Nacional de Desenvolvimento da Educação (FNDE) para o PNAE sejam utilizados na compra direta da agricultura familiar de gêneros que promovam alimentação saudável e adequada à clientela do programa ${ }^{11}$.

Ficam ainda determinados, como parâmetros para a elaboração dos cardápios, a oferta mínima de três porções semanais de frutas e hortaliças e os limites de 10\% da energia total proveniente de açúcar simples adicionado, 15\% a 30\% de gorduras totais, $10 \%$ de gordura saturada, $1 \%$ de gordura trans e $1 \mathrm{~g}$ de sal. Duas outras inovações que a atual legislação inseriu foram a proibição da aquisição de bebidas de baixo teor nutricional e a restrição a $30 \%$ dos recursos para a compra de alimentos com elevados teores de sódio ou de gorduras saturadas ${ }^{11}$.

Finalmente, um recorte importante do marco legal vigente do PNAE é o reconhecimento de que a oferta de alimentação saudável na escola constitui uma estratégia de educação alimentar e nutricional $\left.\right|^{3,11}$, ou seja, as práticas alimentares na escola são vistas como educativas e devem, portanto, estar em sintonia com os conteúdos curriculares.

Esse conjunto de orientações representa, inequivocamente, um dispositivo de aproximação entre a agricultura familiar e uma política pública da maior relevância no Brasil, tanto pelo contingente populacional atendido quanto pelo seu orçamento $^{12}$. Essa aproximação surge como um mecanismo intersetorial com potencial para alavancar transformações significativas no âmbito do fortalecimento da agricultura familiar ${ }^{13}$, concorrendo para uma nova configuração do sistema alimentar em uma perspectiva de construção da sua sustentabilidade e de realização da soberania alimentar.

A Lei $n^{\circ} 11.947 / 2009^{3}$ surge também como possibilidade de aproximação entre a agricultura familiar e a comunidade e de resgate do patrimônio alimentar, reintegrando as dimensões da produção e do consumo de alimentos, processo necessário e urgente ${ }^{14}$, no qual o PNAE pode constituir um elo importante se superadas as dificuldades iniciais ${ }^{10}$.

Argumenta-se que esse processo de aproximação precisa se apoiar em escolhas alimentares 
concretas condizentes com o fortalecimento dessa atividade produtiva e com os princípios da alimentação saudável culturalmente significativa, de forma que a alimentação que o estudante acessa na escola esteja de acordo com essas premissas. Entende-se que os parâmetros apresentados para a elaboração de cardápios, a proibição e a restrição de determinados alimentos sejam orientações que se traduzem como uma tentativa de minimizar a presença de alimentos processados na alimentação escolar.

Corroborando essa interpretação, o projeto que originou a Lei $n^{\circ} 11.947 / 2009^{3}$ trazia, além da definição de alimentos básicos, conceituações para alimentos in natura, semielaborados e elaborados, com prioridade para os dois primeiros tipos, nitidamente associados a menores níveis de processamento ${ }^{15}$. Contudo, essa orientação mais clara sobre o tipo de alimento preferencial para a alimentação escolar foi suprimida do texto sancionado como lei ${ }^{3}$. Mais tarde, o próprio FNDE ${ }^{16}$ assumiu que a Lei $n^{0} 11.947 / 2009^{3}$ tinha por objetivo reduzir a oferta de alimentos industrializados na alimentação escolar.

Nesse sentido, uma avaliação nacional do PNAE realizada em 2004 indicou que os alimentos mais presentes na alimentação escolar eram arroz, macarrão, leite, feijão, achocolatado, bebida láctea, frutas, suco natural, carne enlatada, proteína texturizada de soja e enlatados em geral ${ }^{17}$, o que evidencia a presença de vários alimentos extensamente processados entre os mais utilizados nas escolas brasileiras. Um estudo anterior, realizado em 70 municípios paulistas, identificou que $30,5 \%$ dos alimentos adquiridos para a alimentação escolar em 1995 eram processados ${ }^{18}$. Aliás, o desequilíbrio entre a aquisição de alimentos mais e menos processados, em favor dos primeiros, foi um dos elementos motivadores da descentralização do PNAE ${ }^{19,20}$.

A presença de alimentos formulados foi uma característica marcante do período inicial do programa que foi atenuada, mas não superada, com a descentralização ${ }^{21}$. Estudos recentes realizados na Região da Grande Florianópolis confir- mam essa afirmação: há baixa oferta de alimentos in natura ${ }^{22}$, como frutas e hortaliças ${ }^{23}$. Entretanto, há relatos de municípios e estados que vêm executando o programa de forma diferenciada, com uma maior presença de alimentos in natura nas refeições escolares, adquiridos de pequenos produtores do entorno, o que fortalece a economia local e melhora a qualidade da alimentação escolar 10,14,24.

Contudo, são poucas e localizadas as pesquisas que têm avaliado o perfil dos alimentos que pautam os cardápios da alimentação escolar, e, a despeito dos avanços teóricos identificados na regulamentação do PNAE, ainda não foram publicados estudos que atestem mudanças significativas e abrangentes na concretização do programa quanto a esse aspecto, sendo relevante a atualização de dados dessa natureza. O modelo alimentar dominante do programa ainda parece seguir a lógica da produção em massa, com longas cadeias de abastecimento, o que determina uma relação distante entre consumo e produção ${ }^{10}$.

Nessa perspectiva, apesar do relativamente curto período de tempo transcorrido desde o estabelecimento do atual marco regulatório do PNAE, alguns desafios importantes estão colocados à intencionalidade proposta. Assim, julga-se pertinente refletir sobre eles, na medida em que esse processo pode fornecer elementos para sua superação.

\section{A pauta de alimentos segundo o marco legal do PNAE}

Parte-se do entendimento de que o marco legal vigente do PNAE apresenta algumas lacunas quanto aos alimentos que devam compor os cardápios da alimentação escolar. A legislação oferece uma definição geral de alimento básico, sendo bem específica quanto aos proibidos e aos restritos ${ }^{11}$.

Ao estabelecer que alimentos básicos são aqueles indispensáveis a uma alimentação saudável, o marco legal vigente ${ }^{3,11}$ do programa possibilita a elaboração de cardápios adequados à cultura 
alimentar local, em coerente articulação com as diretrizes do PNAE. Entretanto, embora a 1 ei $^{3}$ confira flexibilidade à gestão do programa ao assim regular sobre os cardápios, essa flexibilidade permite que alimentos não tão saudáveis componham as refeições escolares, desde que respeitem os aspectos culturais, a vocação agrícola da região, a compra mínima da agricultura familiar e as restrições permitidas dentro dos limites pré-estabelecidos.

Buscando configurar uma pauta de alimentos básicos, uma sinalização de quais seriam eles é dada pelo Guia Alimentar Para a População Brasileira ${ }^{25}$, quando estabelece que uma alimentação saudável é constituída por três tipos de alimentos básicos: a) raízes, tubérculos e grãos, preferentemente integrais, b) frutas, verduras e legumes, e c) leguminosas e outros vegetais ricos em proteínas. O Guia Alimentar ${ }^{25}$ explicita que complementam uma alimentação saudável pequenas quantidades de carne, ovos, leite e derivados, mas indica que são os alimentos básicos que devem ter incorporação assegurada em programas públicos de alimentação.

Embora redundante, parece conveniente dizer que os alimentos restritos não podem integrar o grupo de alimentos básicos ou complementares a uma alimentação saudável, mesmo quando pertencem à cultura alimentar local, pois é reconhecido que o perfil de sódio e gordura saturada que os identifica é característico de alimentos de maior extensão de processamento. Entre os restritos, a legislação aponta vários alimentos processados e refeições de conveniência industrializadas. Reafirma-se, portanto, o entendimento, validado pelo $\mathrm{FNDE}^{16}$, de que a legislação está restringindo a presença de alimentos processados na alimentação escolar, embora talvez o faça de maneira pouco contundente.

Considerado, portanto, o limite de 30\% para a aquisição de alimentos restritos, deduz-se que a orientação é para que $70 \%$ dos recursos do PNAE sejam destinados à aquisição de alimentos básicos e complementares saudáveis, e conclui-se que o mínimo de $30 \%$ de aquisições da agricultura familiar não deva ser atingido com alimentos restritos, visto que a aquisição da agricultura familiar deverá "promover a alimentação saudável e adequada à clientela do PNAE" (Art. 19, inciso I) ${ }^{11}$. Essas orientações criam um cenário favorável ao fortalecimento da agricultura familiar e à promoção de hábitos alimentares saudáveis a partir da escola.

A orientação para a utilização dos alimentos básicos não é uma novidade da Lei $n^{\circ}$ 11.947/20093: essa orientação constava da Medida Provisória $n^{\circ} 2.178 / 2001^{5}$ e se manteve ao longo do percurso recente de reformulação do programa. Contudo, essa legislação pontuava que pelo menos $70 \%$ dos recursos deveriam ser destinados à aquisição de alimentos básicos, dando-se prioridade aos in natura e semielaborados.

A seguir, a Resolução/CD/FNDE n 15/200326 chegou a estabelecer uma pauta de alimentos básicos para o PNAE, incluindo banha, toucinho defumado e rapadura, provavelmente visando à valorização das culturas alimentares regionais. Entretanto, as Resoluções/CD/FNDE $n^{\circ} 35 / 2003^{27}$ e $n^{\circ} 45 / 2003^{28}$ suprimiram essa pauta, o que representou um avanço para o programa, já que ela engessava sua execução ${ }^{24}$ e indicava a opção por alimentos de elevado conteúdo de gordura saturada e açúcar.

Já a Lei $n^{\circ} 11.947 / 2009^{3}$ e a Resolução/CD/ FNDE $n^{\circ} 38 / 2009^{11}$ ampliaram a definição de alimentos básicos e suprimiram a preferência pelos in natura e semielaborados. Fica evidente, portanto, ao longo da história do programa, a pouca clareza conferida à expressão alimentos básicos, e a oscilação das definições já empregadas parece refletir as disputas travadas pelos diferentes atores e setores envolvidos nesse processo.

No entanto, a supressão da preferência por alimentos in natura e semielaborados poderia indicar uma expectativa de que as aquisições diretas da agricultura familiar garantiriam a presença expressiva desses alimentos, menos processados e mais saudáveis, no perfil de aquisições do PNAE. Nesse ponto, emerge uma questão: quais alimen- 
tos podem ser adquiridos da agricultura familiar e quais deveriam, preferencialmente, ser adquiridos não só da agricultura familiar mas também e principalmente dela?

Entende-se que a aquisição da agricultura familiar representa uma oportunidade para inserir na alimentação escolar alimentos saudáveis, de baixo ou nenhum nível de processamento, e integrantes dos repertórios alimentares locais, não só quanto ao tipo de alimento, mas também quanto às formas de preparação, articuladas com os modos de comer em família, com a utilização de ingredientes que fazem parte do cotidiano das comunidades.

Argumenta-se que a legislação sinaliza para essa interpretação ao mencionar o respeito à cultura e à tradição alimentar saudáveis, implicando que a oferta de alimentos regionais apresente coerência com o contexto do marco legal vigente do programa, já que a escola é um espaço de aprendizado ${ }^{29}$. Um dos poucos estudos de abrangência nacional sobre a promoção de hábitos alimentares regionais no âmbito do PNAE evidenciou que nem sempre a seleção de alimentos regionais recaiu sobre os mais saudáveis. O estudo mostrou que o charque esteve mais presente do que o peixe na Região Norte; no Nordeste, a predominância de preparações regionais doces gerou excessiva oferta de açúcar; já no Sul, a maior disponibilidade domiciliar de frutas, indicativa de que elas integram a cultura alimentar local, não se refletiu nos cardápios do programa ${ }^{30}$.

Nessa perspectiva, propõe-se investir em releituras das tradições alimentares regionais, já que a globalização e a crescente urbanização vêm homogeneizando essas culturas e invisibilizando esse patrimônio, podendo causar nas novas gerações a impressão de que produtos como pizza e hambúrguer fazem parte dessa tradição. A valorização e a revitalização das práticas alimentares locais saudáveis assumem ainda maior relevância quando se considera que a homogeneização cultural tem contribuído para a perda da pluralidade do mundo, fragilizando as matrizes identitárias das diferentes culturas ${ }^{31}$.
Sugere-se, portanto, planejar os cardápios do PNAE visando à integração de diferentes dimensões: alimento básico, saudável, pertencente à cultura alimentar local e, minimamente dentro dos limites legais, proveniente da agricultura familiar. Nessa lógica, a dieta tradicionalmente muito salgada dos brasileiros, apesar de ter raízes na colonização portuguesa ${ }^{25}$, não pode ser perpetuada a título de preservação da cultura alimentar. Essa noção pode ser extrapolada para alimentos como banha e salame, por exemplo, presentes na cultura alimentar do sul do Brasil, onde foram expressivas as colonizações alemã e italiana, mas que não deveriam integrar a pauta de alimentos do PNAE, especialmente naquilo que é adquirido da agricultura familiar.

Embora os 30\% de recursos permitidos para aquisição de alimentos restritos possam acolher esse tipo de opção, a primeira diretriz da Lei n ${ }^{\circ} 11.947 / 2009^{3}$, que estabelece utilização de alimentação escolar saudável, deveria constituir princípio superior, de forma que essa categoria de alimento não fosse admitida dentro de uma política pública de tamanha relevância.

Utilizando ainda os mesmos exemplos, é comum que pequenos produtores familiares, isoladamente ou organizados em cooperativas, disponibilizem esses produtos. Nesse ponto, surgem outras questões importantes: a agricultura familiar está preparada para fornecer alimentos saudáveis para o PNAE? O entendimento que o agricultor familiar tem sobre a alimentação escolar favorece $\mathrm{o}$ atendimento às demandas desse setor?

Acredita-se provável, em princípio, que a agricultura familiar não esteja preparada para atender à alimentação escolar, pois esses setores não costumavam dialogar entre si, e o atual marco legal do PNAE vem justamente promover essa articulação intersetorial. A relação com a alimentação escolar surge como uma nova oportunidade de fortalecimento da agricultura familiar, mas apenas a legislação pode não ser suficiente para assegurar que essa aproximação resulte em promoção de alimentação saudável na escola. Para que ambos os objetivos sejam atendidos, é 
necessário apoio de órgãos da agricultura que preparem produtores para um planejamento de produção que atenda às demandas da alimentação escolar ${ }^{10}$, e que esteja centrado nos alimentos básicos, não restritos, pouco ou não processados, em quantidades condizentes e com terminação programada para o período letivo.

Além disso, os agricultores familiares estão sujeitos às adversidades climáticas, cujos efeitos podem prejudicar o atendimento da alimentação escolar, requerendo suporte técnico para superar essas questões, de forma a amenizar possíveis conflitos com a gestão do programa que poderiam tornar lento o processo de aproximação esperado. Outra demanda recorrente dos produtores é a necessidade de apoio para implantação de sistemas de produção agroecológica, aos quais o marco legal do PNAE prevê que, quando disponíveis, seja conferida prioridade nas aquisições da agricultura familiar. Esses sistemas representam uma possibilidade de obtenção de melhores preços para os produtos da agricultura familiar pelo valor agregado de qualidade intrínseca e não de processamento.

Já dos setores educação e saúde, importante contribuição pode ser oferecida pela promoção do debate com produtores e técnicos da agricultura familiar sobre o PNAE, suas diretrizes, princípios, objetivos e demandas, num processo de construção de uma visão compartilhada do programa, a fim de que sua aproximação com a agricultura familiar resulte em avanços para ambos.

Diferentemente, na perspectiva da ocupação desse novo e promissor mercado, vem ocorrendo uma busca pela melhoria da produtividade e da lucratividade dos produtores, fundamentada no incentivo ao processamento de seus produtos para que alcancem melhores preços e gerem maior renda ${ }^{32}$. Isso pode, à primeira vista, parecer interessante para a gestão do PNAE, pois o atendimento à legislação, quanto à destinação de $30 \%$ dos recursos para aquisição direta da agricultura familiar, torna-se mais exequível pela aquisição de alimentos mais extensamente processados. Afinal, quantidade muito mais significativa de frutas e de hortaliças ou de arroz, de milho e de feijão é necessária para atender os 30\%, devido ao preço menor desses alimentos em relação aos processados.

Quais seriam, então, os princípios para a configuração de uma pauta de alimentos para o PNAE? Argumenta-se que classificar os alimentos em básicos, restritos e proibidos não garante, necessariamente, a promoção de alimentação saudável na escola ou o enfrentamento do padrão alimentar que vem se consolidando no Brasil. Levando em conta o cenário atual, caracterizado por elevada prevalência de sobrepeso e obesidade, especialmente entre crianças e adolescentes, propõe-se a seguir um conjunto de princípios para a composição de uma pauta de alimentos saudável e sustentável para o PNAE.

\section{Uma proposta para a composição da pauta de alimentos do PNAE}

Considerando que a legislação do PNAE $E^{3,11}$ aponta para a restrição de alimentos ricos em sódio e gordura saturada e estipula limites, para a alimentação escolar, de açúcar, de sódio e de gorduras totais, saturadas e trans, nutrientes presentes em grande proporção em alimentos processados, propõe-se que a seleção de alimentos para o PNAE considere de modo privilegiado o seu grau de processamento.

Estudo baseado na Pesquisa de Orçamento Familiar (POF) de 2002-2003 confirma o perfil nutricional desfavorável dos alimentos de elevado grau de processamento, denominados, pelos autores, de ultraprocessados, especialmente quando comparados a alimentos pouco ou não processados. Esse estudo indicou que o consumo brasileiro de alimentos básicos, como arroz, feijão, frutas e hortaliças, vem declinando em paralelo ao aumento do consumo de produtos ultraprocessados, como biscoitos, pães, embutidos e refrigerantes ${ }^{33}$.

Os resultados da POF de 2008-2009 reforçam essa tendência geral e indicam a redução 
do consumo excessivo do açúcar de mesa e o aumento da parcela desse ingrediente originada de alimentos processados ${ }^{34}$. O também excessivo e já bem estabelecido consumo de sal no Brasil, da mesma forma, recebe substancial contribuição da fração proveniente de alimentos proces$\operatorname{sados}^{25,35}$.

Nesse contexto, tem sido enfaticamente afirmada a urgência de mudanças nas práticas de industrialização de alimentos com vistas à redução do consumo de sal, açúcar e gorduras totais, saturadas e trans ${ }^{25,35}$, visto ser consenso que o aumento do consumo de alimentos processados está entre as principais causas da atual pandemia de obesidade e de doenças crônicas a ela relacionadas $^{36}$. Adensando o conhecimento sobre as implicações desse padrão alimentar, um estudo aplicou o critério do grau de processamento dos alimentos com o objetivo de conhecer a relação entre consumo alimentar de adolescentes e prevalência de síndrome metabólica, concluindo que um elevado consumo de alimentos ultraprocessados esteve associado ao desfecho no grupo avaliado $^{37}$.

Diante dessas evidências, assumindo a premissa de que a escola é um local privilegiado para os mais diversos aprendizados, com grande potencial para que eles se disseminem para a comunidade como um todo, e considerando ainda que o PNAE objetiva promover alimentação saudável, argumenta-se a favor de uma forma de conceber os cardápios da alimentação escolar que resgate os hábitos alimentares saudáveis culturalmente significativos e aproxime a produção do consumo de alimentos.

Um instrumento adequado para atender a essas proposições é a classificação que considera a extensão e o propósito do processamento dos alimentos $^{38}$. Segundo essa classificação, os itens alimentares são alocados em um dos três seguintes grupos: alimentos não processados ou minimamente processados, como cereais, leguminosas, hortaliças, tubérculos, frutas, leite, ovos e carnes (grupo 1); substâncias extraídas de alimentos não processados ou minimamente processados que são utilizadas como ingredientes culi- nários na preparação de alimentos do grupo 1, como óleos, gorduras, farinhas, féculas e açúcar (grupo 2); produtos ultraprocessados e prontos para consumo que são manufaturados pela combinação de ingredientes do grupo 2 com pouca ou nenhuma proporção de alimentos do grupo 1, como produtos panificados em geral, barras de cereal, sobremesas industrializadas, refrigerantes e bebidas adoçadas, molhos prontos, embutidos, sopas desidratadas e macarrão instantâneo, entre outros (grupo 3).

Em seu conjunto, e na forma como são habitualmente combinados entre si no Brasil, alimentos do grupo 1 apresentam alta densidade em nutrientes essenciais, fibra e outros compostos bioativos, baixo teor de gorduras saturadas, açúcares livres e sódio, praticamente ausência de gorduras trans e reduzida quantidade de energia por volume. Assim, são adequados para a composição de cardápios que atendam aos requerimentos nutricionais de escolares, contribuindo para a redução do risco de deficiências nutricionais, obesidade e outras doenças crônicas ${ }^{39}$. Os ingredientes culinários do grupo 2 são, em sua grande maioria, desprovidos de nutrientes essenciais e apresentam elevada densidade energética. Atuam, portanto, diluindo a densidade nutricional e aumentando a densidade energética das preparações culinárias feitas à base de alimentos do grupo 1. Finalmente, produtos do grupo 3, de modo geral, compartilham as características desfavoráveis daqueles do grupo 2, além de, tipicamente, induzirem ao consumo excessivo de energia em função de sua elevada densidade energética, de sua hiperpalatabilidade ou, ainda, do incitamento do consumo compulsivo que usualmente caracteriza a propaganda desses produtos $^{33}$.

Com base na classificação descrita acima, propõe-se que a alimentação escolar seja ofertada, essencialmente, a partir de uma diversidade de alimentos do grupo 1. Os produtos do grupo 2, usados em proporções adequadas, facilitam e diversificam a preparação dos alimentos do grupo 1, o que torna as refeições mais saborosas: nesse 
sentido, podem e devem fazer parte da alimentação escolar. Proporções adequadas de produtos do grupo 2 seriam aquelas que não diluíssem excessivamente a densidade nutricional dos alimentos do grupo 1 e que não tornassem a composição final das refeições escolares excessiva em densidade energética e/ou açúcares livres, sódio, gorduras saturadas ou trans. Essa proporção deve variar, basicamente, em função das pautas de alimentos dos grupos 1 e 2 que compuserem os cardápios escolares.

Com base em cálculos preliminares feitos a partir da pauta de alimentos dos grupos 1 e 2 na POF 2008-200934, concluiu-se que uma relação de 3:1 entre aqueles grupos (em termos calóricos) asseguraria dietas com adequada densidade nutricional e que não excederiam os limites estabelecidos para a densidade energética e para os teores de açúcares livres, sódio, gorduras saturadas e trans. Esses cálculos deverão ser refeitos, em estudos futuros, considerando-se as pautas de alimentos dos grupos 1 e 2 que forem praticadas na alimentação escolar.

Refeições prazerosas e saudáveis podem ser preparadas sem a participação de produtos do grupo 3, retirando, portanto, esses produtos da alimentação escolar. Em função de sua praticidade, visto se apresentarem prontos para consumo, e considerando que, em alguns casos, fazem parte da cultura alimentar brasileira (como pães), produtos ultraprocessados podem ser admitidos na alimentação escolar desde que em pequenas quantidades e a título de complementação, e nunca de substituição, da oferta de alimentos do grupo 1, preparados com proporções adequadas de ingredientes culinários do grupo 2. No caso da inclusão de produtos do grupo 3, a relação entre itens dos grupos 1 e 2 deveria ser aumentada para que o cardápio final se mantivesse saudável. Com base, ainda, em dados da POF 2008-200934, e em caráter preliminar, sugere-se que a participação de produtos do grupo 3 não ultrapasse 15\% do total calórico da refeição e que a participação dos alimentos do grupo 1 supere em três vezes a participação somada daqueles dos grupos 2 e 3 .
Claro está que, dentro de cada grupo, as escolhas devem ser feitas priorizando os alimentos mais adequados a uma alimentação saudável. Assim, no grupo 1, sugere-se a preferência por carnes magras, leite com conteúdo reduzido de gordura, cereais integrais e frutas e hortaliças frescas e de boa qualidade. No grupo 2, aponta-se para a preferência por farinhas integrais e óleos vegetais, com restrição absoluta de banha e de gordura hidrogenada, além do uso parcimonioso de açúcar e sal nas preparações. No grupo 3, respeitada a proibição para bebidas de baixo teor nutricional, recomenda-se a opção por pães, biscoitos e similares, feitos com farinha integral, e por alimentos com reduzidos teores de açúcar, sódio e gordura saturada, livres de gorduras trans. Em relação à alimentação escolar, recomenda-se também a restrição absoluta de balas e de outras guloseimas, salgadinhos industrializados e alimentos fritos, como já previsto por algumas legislações locais ${ }^{40-42}$.

Retomando os parâmetros da Resolução/CD/FNDE n 38/200911 para a elaboração de cardápios, que condizem com as recomendações do Guia Alimentar para a População Brasileira25, acredita-se que destoa desse conjunto a orientação para a oferta semanal mínima de três porções de frutas e hortaliças, o que corresponde à metade da recomendação do Guia ${ }^{25}$ para consumo diário. Propõe-se que, na prática, adote-se a oferta mínima de uma porção de frutas e de hortaliças por refeição escolar, a exemplo do que é proposto pelo mesmo Guia Alimentar ${ }^{25}$. Essa medida, se atendida dentro dos limites da sazonalidade e da territorialidade, poderia, sem grande repercussão no custo, contribuir para uma alimentação escolar mais saudável e articulada à cultura local.

Nesse aspecto, reafirma-se a importância do respeito às culturas alimentares saudáveis, pois a valorização, a produção e a utilização no cotidiano da escola de alimentos locais geram autoestima, incentivam a autossuficiência da comunidade e impulsionam a economia local ${ }^{43,24}$, além de contribuírem para o atendimento das diretrizes do PNAE. Assim, o programa pode se constituir 
um importante vetor de saúde pública e de desenvolvimento local sustentável pelo estímulo à produção e ao consumo de alimentos frescos e saudáveis ${ }^{10}$ adquiridos da agricultura familiar. Essa prática, disseminada na comunidade escolar e, posteriormente, na comunidade no entorno, parece ser a melhor alternativa para a transformação do padrão alimentar brasileiro.

É nessa perspectiva que se propõe uma pauta de alimentos para o PNAE configurada a partir do seu nível de processamento, com vistas a oferecer, nesse espaço, alimentos mais saudáveis e que remetam à tradição alimentar local. A questão deixa de ser quais alimentos e passa a ser que tipo de alimentos: molho pronto ou tomate e cebola, sopa desidratada ou legumes variados, peixe fresco ou sardinha em óleo? Considerando as lacunas deixadas pela legislação, há escolhas a serem feitas e, antes disso, há que se pensar sobre elas.

Argumenta-se que essa proposta está articulada ao atual marco legal do PNAE, que apresenta uma educação alimentar e nutricional que extrapola o currículo, realizada pela abordagem do tema e também pelo desenvolvimento de práticas saudáveis. Oferecer alimentação saudável na escola significa, de fato, oferecer ancoragem para as mensagens do conteúdo curricular, colocando em sintonia o cardápio curricular e o cardápio concreto. A partir da alimentação na escola, a comunidade escolar vai pensar sobre a temática e construir hábitos, afinando paladares e preferências.

Em síntese, reafirma-se que classificar os alimentos em básicos, proibidos ou restritos é opção que não responde, necessariamente, aos desafios colocados pelo padrão alimentar contemporâneo. Nessa proposta, compartilha-se da ideia de que um desafio assume centralidade para o PNAE neste momento: ampliar, disseminar, qualificar e consolidar um corpo de ações de educação alimentar e nutricional para fazer do programa um espaço de promoção da alimentação saudá$v^{2} l^{2}$. Propõe-se que o ponto articulador desse corpo de ações seja a alimentação concreta distribuída na escola.

\section{CONSIDERAÇÕES FINAIS}

Avaliando-se o percurso histórico do marco legal do PNAE, emerge a preocupação constante com uma alimentação saudável: por vezes, claramente explicitada nas recomendações quanto ao tipo de alimento a ser preferivelmente incorporado às refeições; por outras, abrindo lacunas para flexibilizar a execução do programa.

Este ensaio reflete a convicção de que essas lacunas precisam ser preenchidas com uma nova concepção sobre os alimentos básicos saudáveis, que contribua para uma relação com a agricultura familiar que resgate o patrimônio alimentar saudável e promova desenvolvimento local. Não preencher as lacunas identificadas pode significar desperdiçar a mais importante oportunidade que o programa teve, desde a descentralização, para dar um grande salto de qualidade.

Vale salientar que, decorridas quase duas décadas da descentralização do programa, e apesar dos muitos avanços já conquistados, ainda são necessários mecanismos que consolidem a aproximação entre produção e consumo, com aumento da oferta de alimentos menos processados na alimentação escolar. Por força do atual marco legal do programa, que o vincula à agricultura familiar, esse processo ganha novo impulso, mas é urgente garantir que a alimentação oferecida aos escolares seja efetivamente baseada em alimentos in natura ou minimamente processados, já que as políticas públicas parecem vislumbrar para a agricultura familiar uma estrutura de desenvolvimento alinhada à do agronegócio e à da indústria alimentícia, incentivando o setor à mercantilização.

Argumenta-se serem necessárias estratégias de desenvolvimento sustentável tanto para a alimentação escolar quanto para a agricultura familiar, que estejam integradas à noção de soberania alimentar em uma perspectiva intergeracional.

\section{COLABORADORES}

CRPA TEO e CA MONTEIRO colaboraram com a concepção. $O$ trabalho incorpora uma percepção construída por ambos no debate desenvolvido sobre a temática abordada. 


\section{REFER Ê N CIAS}

1. Brasil. Decreto $n^{\circ} 37.106$, de 31 de março de 1955. Institui a Campanha da Merenda Escolar. Diário Oficial da União. 19552 abr; p.6051.

2. Conselho Nacional de Segurança Alimentar e Nutricional. A segurança alimentar e nutricional e o direito humano à alimentação adequada no Brasil: indicadores e monitoramento da constituição de 1988 aos dias atuais. Brasília: CONSEA; 2010.

3. Brasil. Lei $n^{\circ} 11.947$, de 16 de junho de 2009. Dispõe sobre o atendimento da alimentação escolar e do Programa Dinheiro Direto na Escola. Diário Oficial da União. 200917 jun; p.2.

4. Fundo Nacional de Desenvolvimento da Educação. Conselho Deliberativo. Resolução FNDE/CD n³2, de 10 de agosto de 2006. [Internet]. Brasília; 2006 [acesso 2012 mai 31]. Disponível em: <http://www. fnde. gov.br>.

5. Brasil. Medida Provisória n²178-36, de 24 de agosto de 2001. Dispõe sobre o repasse de recursos financeiros do Programa Nacional de Alimentação Escolar e institui o Programa Dinheiro Direto na Escola [Internet]. Brasília; 2001 [acesso 2011 jun 22]. Disponível em: <http:/www.fnde.gov.br>.

6. Schlindwein MM, Silva ABM. Gasto domiciliar com alimentos: uma análise para a região Centro-Oeste. Informe Gepec. 2010; 14(2):129-48.

7. Burlandy L, Maluf RS. Soberania alimentar. In: Conselho Nacional de Segurança Alimentar e Nutricional. A segurança alimentar e nutricional e o direito humano à alimentação adequada no Brasil: indicadores e monitoramento da constituição de 1988 aos dias atuais. Brasília: CONSEA; 2010. Unidade $1-2$.

8. Rigon SA. O acesso à alimentação saudável. In: Conselho Nacional de Segurança Alimentar e Nutricional. A segurança alimentar e nutricional e o direito humano à alimentação adequada no Brasil: indicadores e monitoramento da constituição de 1988 aos dias atuais. Brasília: CONSEA; 2010. Unidade 4.

9. Schmidt MI, Duncan BB, Silva GA, Menezes AM, Monteiro CA, Barreto SM, et al. Doenças crônicas não transmissíveis no Brasil: carga e desafios atuais. Lancet. 2011; 4:61-74. doi: 10.1016/S0140-6736 (11)60135-9.

10. Triches RM, Schneider S. Reconstruindo o "elo perdido": a reconexão da produção e do consumo de alimentos através do Programa de Alimentação Escolar no município de Dois Irmãos (RS). Segur Aliment Nutr. 2010; 17(1):1-15.

11. Fundo Nacional de Desenvolvimento da Educação. Conselho Deliberativo. Resolução FNDE/CD n³8, de 16 de julho de 2009 [Internet]. Brasília; 2009 [acesso 2010 jan 10]. Disponível em: <http:/www. fnde.gov.br>.

12. Fundo Nacional de Desenvolvimento da Educação [Internet]. Alimentação Escolar. Dados estatísticos [Internet]. 2011 [acesso 211 fev 28]. Disponível em: <http://www.fnde.gov.br/index.php/ae-dadosestatisticos>.

13. Azevedo E, Rigon SA. Sistema alimentar com base no conceito de sustentabilidade. In: Taddei JA, Lang RMF, Longo-Silva G, Toloni MHA. Nutr Saúde Pública. Rio de Janeiro: Rubio; 2011. Unidade 34.

14. Triches RM, Schneider S. Alimentação escolar e agricultura familiar: reconectando o consumo à produção. Saúde Soc. 2010; 19(4):933-45. doi: 10.1590/S0104-12902010000400019.

15. Brasil. Subchefia de Assuntos Parlamentares. Projeto de Lei. Dispõe sobre o atendimento da alimentação escolar e do Programa Dinheiro Direto na Escola [Internet]. Brasília; 2007 [acesso 2011 jun 11]. Disponível em: <http://www.planalto.gov. br/ccivil_03/Projetos/PL/2007/msg960-0712 12.htm>.

16. Fundo Nacional de Desenvolvimento da Educação. Coordenação Técnica de Alimentação e Nutrição. Coordenação-Geral do Programa de Alimentação Escolar. Diretoria de Ações Educacionais. Nota Técnica n 001/2009/COTAN/CGPAE/DIRAE/FNDE [Internet]. Brasília; 2009 [acesso 2011 out 3]. Disponível em: <ftp://200.130.5.12/web/alimentacao _escolar/nota_tecnica_res038_2009.pdf>.

17. Brasil. Ministério da Educação. Instituto Nacional de Estudos e Pesquisas Educacionais Anísio Teixeira. Avaliação do programa nacional de alimentação escolar: censo escolar 2004. Brasília: INEP; 2007.

18. Pipitone MAP. Programa de Alimentação Escolar: um estudo sobre a descentralização, escola e educadores [doutorado]. Campinas: Universidade Estadual de Campinas; 1997.

19. Pecorari RCF. Uma proposta de inovação no cardápio escolar baseada na avaliação do Programa de Alimentação Escolar de Piracicaba - SP [mestrado]. Araraquara: Universidade Estadual Paulista Júlio de Mesquita Filho; 2006.

20. Belik W, Souza LR. Algumas reflexões sobre os programas de alimentação escolar na América Latina. Planej Polít Públicas. 2009; 33:103-22.

21. Santos LMP, Santos SMC, Santana LAA, Henrique FCS, Mazza RPD, Santos LAS, et al. Avaliação de políticas de segurança alimentar e combate à fome no período 1995-2002. 4 - Programa Nacional de Alimentação Escolar. Cad Saúde Pública. 2007; 23(11):2681-93. doi: 10.1590/S0102-311X20070 00500005. 
22. Lima EE, Souza AA. Alimentos orgânicos na produção de refeições escolares: limites e possibilidades em uma escola pública em Florianópolis. Rev Nutr. 2011; 24(2):263-73. doi: 10.1590/S1415-5273201 1000200007.

23. Menegazzo M, Fracalossi K, Fernandes AC, Medeiros NI. Avaliação qualitativa das preparações do cardápio de centros de educação infantil. Rev Nutr. 2011; 24(2):243-51. doi: 10.1590/S1415-527320 11000200005 .

24. Carvalho DG. Licitações sustentáveis, alimentação escolar e desenvolvimento regional: uma discussão sobre o poder de compra governamental a favor da sustentabilidade. Planej Polít Públicas. 2009; 32: 115-48.

25. Brasil. Ministério da Saúde. Secretaria de Atenção à Saúde. Guia alimentar para população brasileira: promovendo a alimentação saudável. Brasília: MS; 2006. Série A. Normas e Manuais Técnicos.

26. Fundo Nacional de Desenvolvimento da Educação. Conselho Deliberativo. Resolução FNDE/CD n’15, de 16 de junho de 2003 [Internet]. Brasília; 2003 [acesso 2011 fev 10]. Disponível em: <http://www. fnde.gov.br>

27. Fundo Nacional de Desenvolvimento da Educação. Conselho Deliberativo. Resolução FNDE/CD n³5, de 1 de outubro de 2003 [Internet]. Brasília; 2003 [acesso 2011 abr 19]. Disponível em: <http://www. fnde.gov.br>

28. Fundo Nacional de Desenvolvimento da Educação. Conselho Deliberativo. Resolução FNDE/CD n 45 , de 31 de outubro de 2003 [Internet]. Brasília; 2003 [acesso 2011 abr 19]. Disponível em: <http://www. fnde.gov.br>.

29. Belik W, Chaim NA. O programa nacional de alimentação escolar e a gestão municipal: eficiência administrativa, controle social e desenvolvimento local. Rev Nutr. 2009; 22(5):595-607. doi: 10.1590/ S1415-52732009000500001.

30. Chaves LG, Mendes PNR, Brito RR, Botelho RBA. O programa nacional de alimentação escolar como promotor de hábitos alimentares regionais. Rev Nutr. 2009; 22(6):857-66. doi: 10.1590/\$1415-527 32009000600007.

31. Cuellar JP. Nossa diversidade criadora. Campinas: Papirus; 1999.

32. Pelegrini G, Gazolla MA. Agroindústria familiar no Rio Grande do Sul: limites e potencialidades à sua reprodução social. Frederico Westphalen: URI; 2008.

33. Monteiro CA, Levy RB, Claro RM, Castro IRR, Cannon $\mathrm{G}$. Increasing consumption of ultraprocessed foods and likely impact on human health: evidence from Brazil. Public Health Nutr. 2010; 14(1):5-13. doi: 10.1017/\$136898001000 3241.
34. Instituto Brasileiro de Geografia e Estatística. Pesquisa de orçamentos familiares 2008-2009: avaliação nutricional da disponibilidade domiciliar de alimentos no Brasil. Rio de Janeiro: IBGE; 2010.

35. Sarno F, Claro RM, Levy RB, Bandoni DH, Ferreira SRG, Monteiro CA. Estimativa de consumo de sódio pela população brasileira, 2002-2003. Rev Saúde Pública. 2009; 43(2):219-25. doi: 10.1590/\$0034-8 9102009005000002.

36. World Health Organization. Diet, nutrition and the prevention of chronic diseases. Report of a Joint WHO/FAO Expert Consultation. Geneva: WHO; 2003. WHO Technical Report Series, nº 916.

37. Tavares LF, Fonseca SC, Rosa MLG, Yokoo M Relationship between ultra-processed foods and metabolic syndrome in adolescents from a Brazilian Family Doctor Program. Pub Health Nutr. 2012; 15:82-7. doi: 10.1017/\$1368980011001571.

38. Monteiro CA, Levy RB, Claro RM, Castro IRR, Cannon G. A new classification of foods based on the extent and purpose of their processing. Cad Saúde Pública. 2010; 26(11):2039-49. doi: 10.15 90/S0102-311X2010001100005.

39. Monteiro CA. The big issue is ultra-processing. Commentary. World Nutr. 2010; 1(6):237-69.

40. Estado de Santa Catarina. Lei no 12.061, de 18 de dezembro de 2001. Dispõe sobre critérios de concessão de serviços de lanches e bebidas nas unidades educacionais, localizadas no Estado de Santa Catarina. Diário Oficial. 200120 dez; n. 16.810

41. Estado do Paraná. Lei n 14.855 , de 19 de outubro de 2005. Dispõe sobre padrões técnicos de qualidade nutricional a serem seguidos pelas lanchonetes e similares, instaladas nas escolas de ensino fundamental e médio, particulares e da rede pública. Diário Oficial. 200520 out; n.7.085.

42. Estado do Rio de Janeiro. Lei $n^{\circ} 4.508$, de 11 de janeiro de 2005 [Internet]. Proíbe a comercialização, aquisição, confecção e distribuição de produtos que colaborem para a obesidade infantil, em bares, cantinas e similares instalados em escolas públicas e privadas do Estado do Rio de Janeiro, na forma que menciona [Internet]. Rio de Janeiro; 2005 [acesso 2012 jun 12]. Disponível em: <http://www. jusbrasil.com.br/legislacao/88467/lei-4508-05-riode-janeiro-rj>.

43. Brasil. Ministério da Saúde. Secretaria de Políticas de Saúde. Coordenação-Geral da Política de Alimentação e Nutrição. Alimentos regionais brasileiros. Série F. Comunicação e Educação em Saúde. Brasília: MS: 2002. 